\title{
Els gremis manresans i el suplement del servei de bagatges (I738-I74I). Pressió militar, resistència i litigi a la Catalunya borbònica*
}

\author{
David Ferré Gispets \\ Universitat Autònoma de Barcelona
}

\section{Resum}

A finals de la dècada de I730, el Principat de Catalunya encara es trobava en ple procés d'adaptació a la Nova Planta. Les notables tensions derivades tant del pes de la militarització estructural del nou sistema administratiu com de la corrupció generalitzada en el món local acabaren cristal.litzant en nombrosos plets i resistències en l'àmbit local. L'objectiu d'aquest article és saber com i per què s'esdevingueren aquest tipus de resistències, com es vertebraren i quin va ser el seu desenllaç final. Per aconseguir-ho, prendrem com a principal objecte d'anàlisi el plet entre les autoritats locals de Manresa i els gremis de la ciutat al voltant del cobrament d'un impost local per finançar els «retorns» del servei de bagatges. Mitjançant la consulta de documentació oficial de la Reial Audiència de Catalunya i de l'administració municipal i corregimental, així com de l'àmbit notarial i gremial, procurarem definir una imatge el més completa possible d'aquestes dinàmiques de protesta i litigi a la Catalunya de mitjans del Set-cents.

Paraules clau: Manresa, protesta, bagatges, gremis, Reial Audiència de Catalunya (borbònica), militarització.

* Aquest article s'ha realitzat mercès al programa d'Ayudas para la Formación del Profesorado Universitario (FPU) del Ministerio de Universidades. 
Los gremios manresanos y el suplemento del servicio de bagajes ( 1738 174I). Presión militar, resistencia y litigio en la Cataluña bornónica

\title{
Resumen
}

A finales de la década de 1730 , el Principado de Cataluña aún es encontraba en pleno proceso de adaptación al sistema administrativo de la Nueva Planta. Las notables tensiones derivadas tanto del peso de la militarización estructural del nuevo sistema burocrático como de la corrupción generalizada en el mundo local acabaron cristalizando en numerosos pleitos y resistencias en el ámbito local. El principal objetivo de este artículo es conocer cómo y por qué ocurrieron este tipo de resistencias, cómo se vertebraron y cuál fue desenlace final. Para ello, tomaremos como principal objeto de análisis el pleito acontecido entre las autoridades de Manresa y los gremios de la ciudad por el cobro de un impuesto local para financiar los «retornos» del servicio de bagajes prestado por sus habitantes. Mediante la consulta de documentación oficial de la Real Audiencia de Cataluńa y de la Administración municipal y corregimental, así como de registros notariales y gremiales, procuraremos definir una imagen lo más completa posible de estas dinámicas de protesta y litigio en la Cataluña de mediados del setecientos.

Palabras clave: Manresa, protesta, bagajes, gremios, Real Audiencia de Cataluña (borbónica), militarización.

\section{The guilds of Manresa and the baggage service supplement (I738-I74I). Military pressure, resistance and litigation in Bourbon Catalonia}

\begin{abstract}
At the end of the I730s, the Catalan people were still adapting to the administrative system of the Nueva Planta. Tensions derived from both the weight of the structural militarization of the new bureaucratic system and generalized corruption at the local scale ended up crystallizing in numerous lawsuits and resistance at the local level. The main aim of this article is to understand why those resistances occurred, how were they structured, and what was their usual outcome. To achieve this goal, we will focus our analysis on the lawsuit between the Bourbon authorities of Manresa and the city's unions, based on a distinctive local tax that financed the 'returns' of the military baggage transport commission provided by its inhabitants. By consulting the official doc-
\end{abstract}


uments produced by the Royal Court of Catalonia and the municipal administration, as well as notarial and guild records, we will try to define as complete as possible a picture of this type of protest in I8th-century Catalonia.

Keywords: Manresa, opposition, military baggage transport, guilds, Catalan Royal Court (Bourbon era), militarization.

\section{Integració i protesta a la Catalunya de Felip $V$}

Un dels aspectes més ben coneguts de l'establiment del règim borbònic a la Catalunya del Set-cents és, sens dubte, el seu component militar. Des dels primers treballs de Joan Mercader sobre els organitzadors i l'estructura de la Nova Planta fins a les investigacions més recents de Josep Maria Torras i Ribé i de Joaquim Albareda tocant als darrers compassos de la Guerra de Successió i la repressió de la immediata postguerra, la militarització de totes les esferes de la realitat catalana agafa un paper més que preponderant en les anàlisis i les síntesis centrades en la primera meitat del segle XVIII. ${ }^{\mathrm{I}}$

En les seves obres sobre les tensions i els esclats socials generats per la Nova Planta, Lluís Roura també ofereix una completa descripció de la naturalesa d'aquesta militarització, així com d'algunes de les conseqüències més clares que tingué al llarg del segle. ${ }^{2}$ Segons les seves anàli-

I. Joan Mercader, Els capitans generals, Vicens Vives, Barcelona, 1963. També Joan Mercader, Felip Vi Catalunya, Edicions 62, Barcelona, 1968. Josep Maria TorRAS I RibÉ, Felip V contra Catalunya, Rafael Dalmau, Barcelona, 2005. Joaquim ALBareda, La Guerra de Sucesión de España (I700-I7I4), Crítica, Barcelona, 20Io, pp. 443-524.

2. Lluís Roura, «Subjecció i militarització a la Catalunya del segle XviII», a J. Albareda, coord., Del patriotisme al catalanisme, societat i politica (segles XVI-XIX), Eumo, Vic, 200I, pp. 289-3I. Lluís Roura, Subjecció i revolta al segle de la Nova Planta, Eumo-Pagès, Vic-Lleida, 2005. Lluís RourA, «La força militar borbònica sobre el país al segle XVIII", a J. Sobrequés, coord., Vàrem mirar ben al lluny del desert. Actes del simposi «Espanya contra Catalunya, una mirada històrica (I7I4-20I4)», Generalitat de Catalunya, Barcelona, 20I5, pp. I2I-I4I. 
sis, els aspectes més rellevants de la política militar borbònica a Catalunya es caracteritzaren per l'existència d'una important guarnició militar permanent, la pràctica de quintes, l'establiment de milícies i el desplegament d'un ampli programa de renovació de fortificacions, com també el desarmament i el control de la producció armera del Principat.

De tots els aspectes esmentats, la magnitud de la guarnició permanent en fou un dels més importants. Entre I7I5 i 1725, les xifres de soldats d'infanteria i cavalleria es mantingueren sempre per sobre dels 20.000 homes, i van arribar a pics per sobre dels 30.000 en moments puntuals com el del bienni I7I9-I720. Aquestes magnituds mostraren ja una notable rebaixa al voltant de l'any I749, amb un nombre que oscil.lava entre els I4.000 i els 15.000 efectius. ${ }^{3}$ Francisco Andújar també apunta que durant el mateix regnat de Felip V es devien donar importants rebaixes en el nombre d'unitats presents al Principat, motivats per la política italiana del primer Borbó. ${ }^{4}$ Efectivament, l'agressiva estratègia mediterrània de Felip V i el paper de Barcelona com a centre logístic vital durant les grans expedicions militars cap a Itàlia i al Nord d'Àfrica van fomentar aquests moviments de tropes constants cap al front de guerra i entre les mateixes places catalanes. ${ }^{5}$

Fou precisament la persistent mobilitat de les unitats militars destinades a Catalunya la que generà de manera directa algunes de les tensions i dels incidents més importants del període. Són ben coneguts els costosos efectes dels serveis d'allotjaments i d'utensilis en les poblacions i economies locals catalanes al llarg del Set-cents. ${ }^{6}$ Un altre dels serveis exigits per les unitats militars, sovint obviat per les anàlisis més

3. Lluís Cortada I Colomer, Estructures territorials, urbanisme i arquitectura poliorcètics a la Catalunya preindustrial, Institut d'Estudis Catalans, Barcelona, 1998, II, p. II7. Les xifres esmentades s'extreuen calculant una mitjana de 560 homes per batalló d'infanteria i I20 per esquadró de cavalleria.

4. Francisco Andújar, «De la militarización de Cataluña a los "espacios de integración" de los catalanes en el ejército borbónico tras I7I4", a J. Albareda i A. Alcoberro, coords., Actes del congrés Els Tractats d'Utrecht. Clarors i foscors de la pau. La resistència dels catalans, Generalitat de Catalunya, Barcelona, 20I5, pp. 230-23I.

5. Roura, Subjecció i revolta, pp. 50-53.

6. Roura, «Subjecció i militarització», pp. 305-308. 
generals del tema, és el de bagatges. L'article que presentem pretén aportar una mica de llum sobre el servei de bagatges a Catalunya illustrant alguns dels seus efectes en la població civil i de quina manera els agents locals podien mirar de mitigar-los. Tot això a través de la contextualització i l'estudi d'un intens plet emprès pel conjunt de gremis de la ciutat de Manresa l'any 1738.

Un altre aspecte de l'article és, precisament, l'anàlisi de la intensitat i les bases de la protesta gremial generada pels excessos comesos per les autoritats encarregades del servei. Masses vegades, en les síntesis sobre el Set-cents català, s'ha tendit a acceptar que l'aquietament de la resistència armada austriacista a principis de la dècada de 1720 coincidí amb un "apaivagament» —en paraules de Mercader — general de la protesta i resistència de la població catalana als principis del nou règim. ${ }^{7}$ Aquest fet, alhora, marcaria l'inici d'una etapa d'estreta colllaboració dels habitants del Principat amb les autoritats borbòniques que comportaria grans beneficis compartits, especialment en l'esfera econòmica. ${ }^{8}$ Per bé que resulta una dinàmica innegable si s'aplica estrictament a la resistència de caire austriacista o d'oberta subversió general, aquesta concepció d'apaivagament s'ha acostumat a entendre de manera genèrica com una dòcil submissió del gruix de la població del Principat que es mantingué estable fins a la fi de la centúria. ${ }^{9}$ Una submissió

7. Mercader, Els capitans, p. 93.

8. Roberto Fernández, "Cataluña en las Españas del Setecientos», Pedralbes. Revista d'Història Moderna, 28 (2008), pp. 387-434. Vegeu també el seu indispensable Roberto Fernández, Cataluña y el absolutismo borbónico. Historia y politica, Crítica, Barcelona, 2014.

9. Vegeu com a exemple illlustratiu el pròleg de la tesi publicada de Pedro Voltes Bou, on Jaume Vicens Vives apuntà, potser amb una prosa massa apassionada, que aquest apaivagament és una conseqüència pròpia i directa de la tebior i la poca "profunditat» que tingué la causa austriacista en el poble català, i com l'establiment efectiu de la dinastia borbònica va permetre «engendrar un futuro lleno de promesas y posibilidades». Jaume Vicens Vives, «Prólogo», a Pedro Voltes Bou, El Archiduque Carlos de Austria, rey de los Catalanes, Aedos, Barcelona, 1953, p. I4; És el que també es desprèn de les paraules emfattiques emprades per Ferran Soldevila per referir-se a les actituds del poble català després del conflicte successori, quan proclama que «els ca- 
només trencada de manera espontània a través dels avalots, motins i esclats motivats per les quintes o, fins a mitjans de la dècada de I730, per un austriacisme larvat encara resistent. ${ }^{\mathrm{IO}}$ Aquesta tendència analítica acostuma a prestar poca atenció en aspectes com l'existència de mecanismes alternatius de protesta i reclamació que no comportessin una insubmissió directa, manifesta i de caire insurreccional. Mecanismes de protesta i reclamació integrats en el mateix règim de la Nova Planta, que en el context de la Catalunya de ple segle Xvin podien ser un vehicle tan útil com viable per aconseguir un alleujament dels efectes més onerosos i durs del nou règim, com, per exemple, la militarització administrativa de l'esfera local. ${ }^{\text {II }}$ Una de les primeres experiències reivindicatives canalitzades dins l'ordenament de la Nova Planta, la podem trobar en les diverses propostes de reforma presentades pels I7 procuradors corregimentals catalans, reunits l'any I723, amb la missió de distribuir els 900.000 pesos del Cadastre d'aquell any. ${ }^{\mathrm{I2}}$ Precisament, la setzena de les seves propostes versà sobre els excessos i les irregularitats derivades del servei de bagatges, que és l'objecte del nostre treball.

D'altra banda, l'ús dels gremis i les confraries d'oficis com a plataformes de protesta i denúncia no és quelcom desconegut, especialment a partir de mitjans de segle. Ja fou observat per Pere Molas en el cas mataroní i per Enric Tello en el seu famós estudi sobre la Cervera de

talans anaven a assajar d'esdevenir "província"”, a Ferran Soldevila, Història de Catalunya, Alpha, Barcelona, 1962, III, p. II70.

IO. Ernest LluCH, «El programa polític de la Catalunya austriacista», a J. Albareda, coord., Del patriotisme al catalanisme. Societat i politica (segles XVI-XIX), Eumo, Vic, 200I, I29-I67. Roura, Subjecció i revolta, pp. 79-217.

II. Compartim, en aquest cas, les reflexions al respecte que enceten les conclusions del darrer treball de Josep Maria ToRras i Ribé, Misèria, poder i corrupció a la Catalunya borbònica (I7I4-I808), Rafael Dalmau Editor, Barcelona, 2020, pp. I89-190.

I2. Arxiu de la Corona d'Aragó (ACA), Reial Patrimoni (RP), Batllia General del Reial Patrimoni (BGRP), Processos, 1923, núm. 4, As. El document fou analitzat i transcrit per Mercader a Joan MERCADER, «Una visión pesimista de la economía catalana después de la guerra de Sucesión», Estudios de Historia Moderna, 5 (1955), pp. 4II-4I9. 
mitjans del Set-cents, així com per Torras i Ribé des d'una perspectiva cronològicament i geogràfica més àmplia. ${ }^{13}$ És precisament aquest darrer qui, en una recentíssima obra de gran interès, ha tornat a investigar aquest aspecte $\mathrm{i}$ ha recollit un gran nombre de conflictes, pugnes i plets esdevinguts en l'esfera local a causa dels abusos de les autoritats al llarg del Set-cents català. ${ }^{\mathrm{I}}$ Com es desprèn de la seva recerca en les fonts oficials borbòniques, a partir de la dècada de 1740 bona part de les classes populars i mitjanes de viles i ciutats d'arreu de la geografia catalana començaren a canalitzar les seves protestes i demandes contra els excessos governatius a través dels gremis. ${ }^{15}$ Unes demandes que, amb el temps, i tot i les intenses reticències per part de les autoritats reials, acabaren plantant la llavor dels nombrosos canvis institucionals esdevinguts al Principat a finals de segle.

El cas que vertebra el nostre treball —que no ha estat tractat en l'esmentada obra de Torras i Ribé — tot i les particularitats pròpies del context manresà podria perfectament constituir un dels exemples més primerencs d'aquesta dinàmica reivindicativa. Mitjançant una deguda contextualització cronològica i geogràfica, així com una recerca conjunta en fonts oficials i privades, ens sembla que podem aportar una mica més de llum sobre la capacitat litigiosa de les corporacions catalanes durant el regnat de Felip V.

I3. Pere Molas, Societat i poder politic a Mataró, I7I8-1808, Rafael Dalmau, Barcelona, 1973, pp. II7-I3I; Enric Tello, Visca el rei i les calces d'estopa! Reialistes i botiflers a la Cervera set-centista, Crítica, Barcelona, I990; Josep Maria ToRras I RibÉ, Els municipis catalans de l'Antic Règim, I453-1808, Curial, Barcelona, 1983, pp. 317-330.

I4. Torras i Ribé, Misèria, poder, pp. 7-Io. També resulta d'interès en aquest aspecte l'article de José María Delgado Ribas, «La corrupción como mecanismo de fidelización. El caso de la Cataluña borbónica (I7I4-I770)», Illes $i$ imperis, I6 (2014), pp. 7I-88.

I5. Torras i Ribé, Misèria, poder, pp. 97-II4. 


\section{Manresa a l'acabament de la postguerra de Successió}

L'abrandada defensa de la causa de Carles III duta a terme per les autoritats locals manresanes durant la Guerra de Successió va acabar tenint unes conseqüències cruelment oneroses per la ciutat. Amb la capitulació final de Barcelona i Cardona el setembre de I7I4, el panorama que s'obria resultava veritablement poc esperançador per a una població esgotada per dècades de guerra.

La reconstrucció de les 522 cases destruïdes durant el gran incendi d'agost de I713 s'allargà durant anys. La reparació de les muralles i l'erecció de les noves casernes, necessàries per acomodar la guarnició militar de la ciutat, havien de córrer a compte de les maltractades arques del comú manresà. ${ }^{16}$ Tota aquesta despesa se sumà a la llosa extraordinària que ja comportava la nova fiscalitat nascuda els darrers anys de la guerra, institucionalitzada a partir de i7i6 en l'impost del Reial Cadastre. Aquestes condicions empitjoraren les perspectives d'eixugar l'enorme deute acumulat, i pressionaren notablement les noves autoritats municipals per aconseguir concòrdies amb els seus creditors principals. ${ }^{17}$

La responsabilitat de gestionar aquesta situació recaigué en mans dels nous consellers municipals borbònics. Alguns d'ells ja havien servit Felip V durant la seva primera etapa de govern (I7OI-I705), per exemple Jaume de Llissach, que recuperà el càrrec de veguer retirat per les autoritats austriacistes el 1705. Uns altres assoliren aquestes dignitats pels serveis i la fidelitat demostrades durant la guerra, com ara Carles Riu i Rovira, Josep Soler de la Plana, Jacint Torres de Bages o Joan Pujol. ${ }^{18}$ Aquests homes $\mathrm{i}$ alguns altres de trajectòria similar acabaren ocupant

16. Francesc Serra i Sellarés, «Les conseqüències econòmiques de la Guerra de Successió a Manresa", a M. Torras i Serra, coord., Manresa, de la Guerra dels Segadors a la Guerra Gran, Centre d'Estudis del Bages, Manresa, 20I4, pp. I87-220.

17. Llorenç Ferrer Alós, «Finances i deute municipal a Manresa en els segles XVII I XVIII", a M. Torras i Serra, coord., Manresa, de la Guerra dels Segadors a la Guerra Gran, Centre d'Estudis del Bages, Manresa, 20I4, pp. I32-I46.

I8. Mercader, Felip V, pp. 4I6-4I8. 
diferents càrrecs de responsabilitat local que anaren des de les regidories —algunes d'elles vitalícies i hereditàries — fins a les alcaldies majors o tinències de corregidor. ${ }^{19}$ La màxima autoritat dins del naixent corregiment de Manresa — que englobà la vegueria de Manresa i les sotsvegueries de Berga, Moià i el Lluçanès - correspongué al corregidor. ${ }^{20}$ Aquesta figura de govern d'arrel castellana substituí el càrrec de veguer a partir de i718. A Manresa, com a la resta del Principat i del Regne de València, aquests càrrecs recaigueren gairebé del tot en mans militars durant pràcticament tot el segle. ${ }^{21}$

Així doncs, els anys d'immediata postguerra a la ciutat es caracteritzaren per una continuïtat de les misèries $i$ de les càrregues econòmiques heretades de la Guerra de Successió combinada amb un procés radical de canvi de l'administració local i regional. Els importants desajustos econòmics causats per la inestabilitat monetària de 1717 i i 1718 també es deixaren sentir a Manresa amb xocs entre la tropa i els venedors locals a les places de la ciutat. ${ }^{22}$ El zenit d'aquests processos coincidí temporalment amb una nova crisi militar originada per l'agressiva política mediterrània de Felip V. A partir de la tardor de I7I8 i durant tres anys, Catalunya tornà a ser escenari principal d'un conflicte, en aquesta ocasió la Guerra de la Quàdruple Aliança (I7I8-I72I). Per bé que Manresa restà lluny del front pirinenc, les accions de les partides armades aus-

19. Rafael Cerro Nargánez, «Una magistratura castellana en Cataluña, Los alcaldes mayores del corregimiento de Manresa en el siglo xviII", Cuadernos de Historia Moderna, 34 (2009), pp. 7-3I.

20. Josep Maria Gay Escoda, El corregidor a Catalunya, Marcial Pons, Barcelona, 1997.

2I. Per a un apropament als xocs i les tensions institucionals propis de la «militarització» de la figura corregimental a l'antiga corona d'Aragó dins del conjunt de la península, vegeu Enrique GIMÉNEz López, «El debate civilismo-militarismo y el régimen de Nueva Planta en la España del siglo Xviı»", a Enrique Giménez López, Gobernar con una misma ley: sobre la Nueva Planta borbónica en Valencia, Servei de publicacions de la Universitat d'Alacant, Alacant, 1999, pp. 13-47.

22. Josep Maria ToRras I Ribé, «La resistència cívica contra el règim borbònic a Catalunya: el "tancament de botigues" de 1717-1718", Pedralbes. Revista d'Història Moderna, 28 (2008), p. 360. 
triacistes i el constant pas de contingents borbònics i esquadres de paisans tornà a estroncar qualsevol indici de recuperació. No fou fins a mitjans de la dècada de 1720 quan es començaren a donar els primers símptomes d'estabilització. La consecució de les concòrdies amb els creditors de l'ajuntament entre el I 72 I i el I 724 en poden ser un exemple ben illustratiu.

\section{La situació de Manresa en el mapa militar del Principat}

Malgrat el notable canvi de conjuntura econòmica, demogràfica i administrativa que la ciutat experimentà a partir de 1726 , algunes de les dinàmiques més pròpies dels primers anys de la postguerra es mantingueren ben vives durant les dècades següents. Com ja s'ha apuntat, l'innegable component de militarització que comportà el nou règim borbònic es materialitzà en una presència notable d'efectius en guarnició permanent, i en trànsit, a Catalunya. Manresa ocupava un lloc de gran importància dins del mapa casernari català. La seva posició geogràfica central dins del Principat la convertia en un punt d'aturada obligatòria per a aquelles unitats que es destinessin a les places de la Catalunya Central o del Pirineu Central, ja fos Manresa mateix, Cardona, Berga o la Seu d'Urgell. Totes aquestes viles i ciutats havien adequat edificis com a casernes des de I7I8. Algunes, com Solsona o Berga, projectant nous edificis situats dins de les seves respectives fortaleses. ${ }^{23}$

A Manresa, les autoritats locals designaren com a caserna un edifici situat al Puigcardener, a prop de la Seu. Amb les tensions de 1719 i I720, l'habitacle per un sol batalló quedà massa petit i en molt mal estat. ${ }^{24}$ La pressió causada pel trànsit constant de tropes motivà progressius engrandiments, actuacions i remodelacions durant les dues dècades següents. Mentrestant, de manera habitual, la totalitat dels

23. Cortada i Colomer, Estructures territorials, pp. 85, IOO-IOI, IO4, I22.

24. Arxiu Comarcal del Bages (ACBG), Arxiu Municipal (AM), Cartes rebudes per l'ajuntament, I717-1770, lligall I085, Carles Riu i Rovira a Consellers de Manresa (3 de març de 1719). 
oficials de cada batalló i alguns dels soldats rasos s'allotjaven en cases particulars. ${ }^{25}$

\section{Els serveis de bagatges $i$ la seva gestió legal a Catalunya (del s. XV al XVIII)}

El servei de bagatges consistia en la mobilització d'animals de càrrega $\mathrm{i}$ dels seus amos de les ciutats, viles i llocs situats al voltant de la plaça on s'allotjava una unitat militar, amb l'objectiu d'assistir la tropa durant el trànsit d'una plaça a una altra. Per bé que aquesta pràctica es remunta a l'Antiguitat, va seguir present arreu d'Europa durant tota l'època medieval, tant per assistir les hosts nobiliàries com les tropes pròpiament reials.

Una de les primeres legislacions catalanes encarades a evitar els excessos que solien esdevenir-se quan els oficials reials sollicitaven aquest tipus de serveis va ser el capítol vint-i-tresè de les Corts de Montsó de I470, presidides per Joan II durant la Guerra Civil Catalana (I4621472). ${ }^{26}$ Aquest capítol recollia la deliberació i ordre promulgada a Tarragona durant el Parlament de I465, on es prohibia que qualsevol «Alcayd o Capita de qualsevol Ciutat, Vila, Castell, Loc o Fortalesa» pogués prendre per la força i sense pagar cap mena de gènere de llenyes, palles, vitualles o atzembles. La ratificació de Montsó es va fer adduint els reiterats incompliments comesos els anys anteriors tot i les ordres expressades.

Ja en plena època moderna, durant les corts de 1599 presidides per Felip III s'aprovà el capítol quaranta-vuitè en què es prohibia poder prendre per la força carretes o animals de pagesos «a obs de traginar fustes, $o$ altres coses per la fabrica de les galeres de Sa Magestat y forta-

25. Algunes mostres a ACBG, AM, Acords, I - 45, s/f (Io d'agost deI723), I - 48, s/f (4 de maig de 1736) o a ACGB, Arxiu Històric de Protocols de Manresa (AHPM), Notari Maurici Bohigas, lligall 488I, ff. 63v-65r, (I5 d'octubre de 1724).

26. Constitucions y altres drets de Catalunya, compilats..., I704: llibre I, títol LVIII, núm. III, 138 . 
lezas, sinó tant solament de aquelles que tindran carros alloguer». ${ }^{27}$ En cas que no hi haguessin professionals del transport disponibles, es permetia llogar els carros i atzembles locals sempre que es pagués per avançat i no es trobessin entre els mesos de més activitat agrícola, compresos entre juny i mig desembre. A més a més, s'incrementava el preu per quintar a transportar en dos diners més sobre el preu corrent. L'esclat de la Guerra de Separació l'any i640 i l'agreujament de la pressió militar multiplicà exponencialment el nombre de serveis a executar. L'ambient constant d'excepcionalitat militar afavorí la cruesa i els excessos de les unitats en trànsit. ${ }^{28}$

Amb l'arribada del segle XviII s'obriren unes noves Corts presidides per Felip V entre els anys I70I i I702. L'experiència popular de les campanyes de finals del Sis-cents va motivar que el servei de bagatges fos regulat en un capítol propi i desvinculat d'altres serveis com el d'allotjaments. En aquest cas, el capítol setanta-vuitè recollí algunes de les desmesures que es donaven en molts pobles, «obligantlos moltas vegadas, à que passen los límits se tenen destinats per la repartició de dits trànsits». ${ }^{29} S^{\prime}$ acordà llavors que, com a màxim, cada poble sols havia de proveir dos bagatges per cada companyia d'infanteria i quatre per companyia de cavalleria. Així mateix, no es podia carregar el bagatge de més de Io arroves de pes..$^{30}$

De nou, amb l'inici de la Guerra de Successió a Catalunya i l'entronització de l'Arxiduc d'Àustria com a Carles III, la matèria tornà a ser discutida i legislada, tenint present les renovades necessitats militars que havien de gestionar les autoritats austriacistes. En el capítol trenta-quatrè de les corts de 1705-1706, s'augmentà el màxim de bagatges per companyia d'infanteria a tres i per companyia de cavalleria a sis. A més a més, s'assegurà que cap poble hagués de prestar bagatges a noves

27. Ibidem, llibre IV, títol XXV, núm. XXIV, 305.

28. Antonio Espino, Las Guerras de Cataluña. El teatro de Marte, I652-I7I4, EDAF, Madrid, 20I4, pp. 343, 356, 380.

29. Constitucions, capitols $i$ actes de cort I70I-I702 i I705-I706, Parlament de Catalunya i Generalitat de Catalunya, Barcelona, 2006, p. 72.

30. Uns I 40 quilos. 
unitats mentre tinguessin atzembles servint altres cossos. També s'afermà la importància del pagament en efectiu dels serveis pels mateixos oficials encarregats de la seva gestió i la impossibilitat de canviar de destí una vegada s'havia iniciat el trànsit. ${ }^{31}$

Pel que fa a les tropes borbòniques, durant la guerra la regulació del servei quedava fixada a través de diverses ordenances militars, començant per la de 30 de desembre de I706. Més endavant, es regulà amb les ordenances generals de 12 de juliol de $\mathbf{1 7 2 8}$. En aquest cas, en el setzè títol del segon llibre de les ordenances generals s'explicità clarament que cap oficial

sin orden particular, pueda en Lugar alguno, transitando, pedir bagage alguno, mayor ni menor; y si por algún accidente le[s] necesitaren sin la referida orden, han de pagar por cada galera de seis mulas, veinte y quatro reales al día; y si fuere de quatro, diez y seis; y si carro con dos mulas o dos bueyes, doce reales; si bagage mayor, ocho al día; y si menor, quatro, prohibiendo también, que con ningún motivo puedan obligar a que los expressados bagages pasen de un tránsito a otro. ${ }^{32}$

Com es pot extreure d'aquestes línies, les persones implicades en el servei serien pagades per les autoritats militars amb un preu taxat i fix, segons el tipus de bagatge, els adherents que aportaven i els dies que s'hi implicaven. El temps es calculava des que es deixava la plaça d'origen fins que s'arribava a la de destí. Els bagatges majors podien ser bous, cavalls o mules, mentre que els menors es referien generalment als ases.

Aquestes bases legals, tot i la seva concisió, només es mantingueren en vigor fins a la publicació de la reial cèdula de Io de març de 1740 titulada «Sobre los bagages con que los Pueblos deben assistir a la Tropa y precios a que ésta los ha de satisfacer». La necessitat de clarificar novament els límits del servei naixia de les «continuadas disputas que producen reiteradas tropelías en agravio de Particulares y pueblos con

31. Constitucions, capitols $i$ actes de cort, pp. 87-88.

32. José Antonio Portugués, Colección General de las Ordenanzas Militares, sus innovaciones, y aditamentos, dispuesta en diez tomos, Impremta d'Antonio Marín, Madrid, I765, I, pp. 535. Ibidem, vol. III, pp. I78-I79. 
Incomodidad de los Cuerpos y Oficiales y atraso de mi Servicio». ${ }^{33}$ Les reclamacions dels gremis manresans, per bé que centrades en un aspecte no explicitat per les ordenances, seran una més d'aquestes nombroses queixes recollides per les autoritats civils i militars del Principat.

De la mateixa manera que en el cas dels allotjaments i de les casernes, el pes de la gestió d'aquest servei quedava a les mans de les autoritats locals. El corregidor, com a màxima autoritat militar regional, s'encarregava de repartir el nombre de bagatges majors i menors per cada població dins de la seva jurisdicció. Un cop trameses les ordres, els batlles, justícies i regidors locals havien de gestionar els repartiments o sortejos de les persones i les bèsties que havien de presentar-se al punt de reunió.

Per la mateixa naturalesa del servei, els individus més afectats pel seu acompliment eren els arriers, traginers o llogaters de mules, que disposaven de tota la infraestructura necessària per al transport de càrrega. Tanmateix, els artesans, els pagesos emfiteutes i els seus masovers que posseïssin animals de tir també entraven en el repartiment del servei. Tot i així, com amb la resta de contribucions - tant reials com locals - hi havia un conjunt de persones que quedaven excloses de pagar o servir, ja fos per raó de privilegi de noblesa, per privilegi eclesiàstic o per ostentar el fur militar. Bona part dels mateixos regidors, els arrendadors de drets, els familiars del Sant Ofici i els empleats en contractes de proveïment militar solien entrar dins d'aquestes categories.

\section{El servei de bagatges a Manresa fins l'any 1738}

Larrel del problema que originà la persistent batalla legal empresa pels gremis manresans es remunta a l'any I719. Com ja s'ha apuntat, aquell any Catalunya esdevenia novament un camp de batalla, immersa en la Guer ra de la Quàdruple Aliança. L'establiment del front de guerra a la frontera pirinenca motivà que Manresa es convertís en un punt de pas impres-

33. Portugués, Colección General, III, p. 408. 
cindible, tant per a les unitats dirigides cap al combat, com per a les que es retiraven a les casernes d'hivern. ${ }^{34}$

La gran quantitat de serveis a prestar, juntament amb la duresa de les condicions econòmiques de la postguerra, van motivar que molts dels propietaris de la ciutat preferissin vendre's els animals de tir i de càrrega per no haver de seguir suportant el pes de la contribució. ${ }^{35} \mathrm{La}$ pèrdua de dies de treball i la magresa de la paga, que ascendia tan sols a sis rals d'ardit diaris per bagatge major i quatre rals per bagatge menor, no eren al.licients prou atractius per mantenir les atzembles. A més a més, sembla que la pressió militar estroncà qualsevol miratge de repartiment del servei, que requeia gairebé del tot sobre els membres del gremi de traginers de la ciutat.

Així doncs, les autoritats locals i les corporacions d'oficis de la ciutat arribaren a un acord per pal-liar aquesta dinàmica tan perjudicial per al Reial Servei. Els síndics dels gremis van acceptar realitzar un repartiment entre els seus membres, sense cap intervenció de l'ajuntament o de les justícies locals, amb l'objectiu de recollir prou diners per pagar les jornades de retorn — o «retorns»— dels individus que aportaven els bagatges. Aquest tribut afectava tots els confrares del gremi, tant els que eren propietaris d'atzembles com els que no ho eren, de manera que així es redistribuiia el pes del servei. Segons apunten els testimonis gremials, els repartiments es feien cada vegada que hi havia un pas de tropes i no únicament una vegada l'any. Així doncs, les quantitats a repartir podien variar notablement segons les necessitats militars de la monarquia. Aquest fet es deixà notar especialment a partir dels primers anys de la dècada de I730, quan la maquinària militar borbònica tornà a posar-se en marxa amb la conquesta de la plaça nord-africana d'Orà (I732) i les

34. David Ferré Gispets, «Las fronteras pirenaicas ante la guerra de la Cuádruple Alianza (I718-1720)", Principe de Viana, 272 (2018), p. I207. Per a un apropament general al front català d'aquest conflicte, vegeu Enrique Giménez López, «La postguerra oblidada de Catalunya. La Quàdruple Aliança davant del revisionisme d'Utrecht (I719-1720)", Afers, 52 (2005), pp. 623-649.

35. Arxiu de la Corona d'Aragó (ACA), Reial Audiència (RA), Registres, núm. I64, ff. 96v-99r (I8 d'abril de I74I). 
campanyes italianes de I733-I738. Com en ocasions anteriors, Catalunya actuà com a plataforma logística d'aquestes operacions que revitalitzava els moviments d'unitats cap a un o altre punt del Principat.

Entre el I733 i el I738, el corregidor de Manresa i el seu alcalde major organitzaren 36 serveis de bagatges..$^{36}$ D'aquests, 26 sortiren o arribaren a Manresa. Els Io restants consistiren en trànsits d'unitats entre dos pobles dins de la subdelegació manresana del corregiment, com ara Sallent, Sant Fruitós, Calders o Castellterçol. La seva distribució al llarg del període no era gens homogènia. Mentre que els anys I733, I734 i 1735 les xifres es mogueren entre un i quatre serveis anuals, els anys I735, I737 i I738 acumularen el 8I \% dels passos de tropes amb 9, Io i Io serveis respectivament. No resulta estrany, doncs, que després d'experimentar un augment tan notable com el que veiem a partir de I735, alguns dels gremis i corporacions de la ciutat es replantegessin la validesa de les mesures instaurades el I7I9.

\section{Els memorials dels gremis}

Les confraries capdavanteres en la protesta i litigació contra els suplements de bagatges foren les relacionades amb l'art de la seda. Aquest era, sense cap mena de dubte, el sector productiu més afavorit per la recuperació econòmica manresana després de la Guerra de Successió. ${ }^{37}$ Els artesans del ram de la seda, ja fossin torcedors, velers, galoners o cordoners, van acabar dominant l'esfera productiva manresana a mitjans de segle, i arribaren a constituir el 56,2\% de tots els artesans de la ciutat l'any $\mathrm{I} 788 .{ }^{38} \mathrm{~A}$ causa de la seva importància econòmica i del pes

36. Vegeu el quadre I.

37. Àngels Solà Parera, Llorenç Ferrer-Alòs, Lluís Virós Pujolà, Yoshiko Yamamichi, «Silk textiles, crisis and adaptative strategies in Catalonia, I770-1850s (Barcelona and Manresa)», Continuity and Change, 35-I (2020), p. 56.

38. Joaquim SARret i Arbós, Història de la indústria, del comerç $i$ dels gremis de Manresa, Impremta Sant Josep, Manresa, 1923, p. I84. Solà Parera, Ferrer-Alòs, Virós Pujolà, Yamamichi, «Silk textiles», pp. 56-57. 
demogràfic, constituïen un dels collectius més damnificats pels pagaments dels «retorns» dels bagatges.

Així doncs, durant els primers dies del I738, el veler Francesc Llor, com a representant i apoderat del gremi de Nostra Senyora del Remei de velers, galoners i cordoners inicià el llarg procés de litigació que ens ocupa enviant dos memorials de protesta a l'ajuntament i al corregidor. Llor hi reclamava un aclariment explícit a les autoritats sobre la base legal de l'impost dels «retorns» i la inconveniència de continuar-lo cobrant en cas que no existís un mandat reial que ho obligués. ${ }^{39} \mathrm{El}$ veler sostenia la seva demanda adduint l'augment constant de les quantitats a pagar, que de vegades arribaven a superar les quatre-centes lliures.

Lajuntament i el corregidor els compel.lien a seguir pagant el servei basant-se en la consuetud de la pràctica, mantinguda sense novetat des de I719. Ja en aquest moment, els velers aconseguiren sumar gairebé totes les altres confraries d'artesans de la ciutat en un front comú contra l'impost. El dia 20 de febrer de 1738 , els gremis ratificaren la seva posició amb nous recursos, negant-se a seguir pagant tot i els continuats advertiments de les autoritats. Finalment, el corregidor Fernando de Guzmán es valgué de l'agutzil reial Joan Bohigues per arrestar els prohoms dels gremis. Cinc d'ells acabaren a les presons reials de la ciutat, mentre que la resta evitaren la presó refugiant-se a les esglésies i capelles de l'entorn.

La gravetat de la situació motivà que l'afer fos discutit en instàncies superiors i que arribés al capità general de Catalunya, el comte de Glimes. Finalment, l'assumpte s'acabà derivant a la Reial Audiència de Catalunya mitjançant una consulta. El dia I6 de juny, l'Audiència es pronuncià per primera vegada en contra dels gremis manresans, obligant-los a continuar pagant el suplement «en la misma forma y baxo las mismas reglas que lo han executado desde el año mil setecientos y diez y nueve, sin hazerse novedad alguna en este assumpto».. ${ }^{40}$

39. ACBG, AM, Acords, I-50, s/f ( 28 de juliol de 1738 ).

40. ACA, RA, Registres núm. I60, ff. 67v-68r (I6 de juny de I738). 
La decisió fou tramesa a De Guzmán, que seguidament la comunicà als representants de cadascuna de les setze corporacions manresanes en una reunió general celebrada el dia 7 d'agost. Els representants dels gremis acataren la decisió comprometent-se a satisfer les quantitats impagades fins aquell moment. Amb tot, seguidament sol-licitaren i aconseguiren el permís per poder recórrer el veredicte a instàncies superiors. ${ }^{4 \mathrm{I}}$

Francesc Llor, que just després de la primera resolució de l'Audiència ja havia enviat un nou memorial de protesta com a representant del seu gremi, remeté una segona instància el dia Io d'agost, aquesta vegada com a apoderat de totes les confraries de la ciutat. ${ }^{42}$ En aquest darrer memorial, a més dels arguments de la manca d'una legislació clara i dels danys econòmics, s'hi sumaren les queixes obertes sobre els continus excessos comesos pel corregidor i els seus homes en la gestió del servei de bagatges més enllà dels «retorns».

En paraules del memorial:

[...] el Corregidor, su Theniente y Alguaziles, haciendo composiciones a algunos por excusarles de ir a bagages, dándolos a los que no les compete y no pagando los retornos que hacen contribuir a los Artesanos y haziendolos satisfacer de más bagages q[ue] no han ido. Pidiendo q[ue] pendiente la Consulta sobre su recurso, se mande al Corregidor de Manresa se abstenga de cobrar de los suplicantes dichos retornos q[ue] les amenaza percibir con pena de açotes.

El notari manresà Jaume Tomàs recollí un total de vuit testimonis d'aquestes males pràctiques entre els dies I4 i 20 de juliol del mateix any. Maurici Coma i Magí Firmat testificaren que, com a criadors de matxos, els agutzils solien embargar-los els animals per anar de bagatge sense pagar-los la majoria dels «retorns», per bé que ells dos sempre havien pagat les talles fetes pels seus respectius gremis amb aquest ob-

4I. ACBG, AHPM, Notari Francesc Ratllat i Fargas, lligall 4977, ff. I64V-I66r (7 d'agost de I738).

42. ACA, RA, Registres núm. 232, ff. 8 or (28 de juny de I738) i ff. 97v (Io d'agost de 1738$)$. 
jectiu. ${ }^{43}$ El blanquer Onofre Coma anà més enllà i denuncià que «no se paguían retorns de bagatges perquè los Alguasils los cobren dels Gremis, y no[e]ls pagant a aquells qui han fet anar a bagatge». ${ }^{44} \mathrm{~A}$ més d'aquests cobraments irregulars, els agutzils extorsionaven alguns propietaris d'atzembla com Jerònim Comelles, que es lamentava que cada any, quan es trobava en «lo temps més ocupat de arreplegar los grans y veremas de mos arrendaments no han faltat dits Alguasils en conposarme quant de un real de vuÿt, quant de set reals y quant de una passeta a $[\mathrm{m}] \mathrm{b}$ la amenasa que sinó me faran anar a bagatge».45

La relació entre els gremis i els homes del corregidor semblava tensar-se perillosament. Cal recordar que l'ordenació administrativa de Nova Planta afermà el control reial dels gremis a partir de l'any I716, obligant al fet que tots els cònsols i prohoms de confraria fossin formalment nomenats pel Reial Acord. El I7I8, aquesta autoritat fou finalment adjudicada en exclusiva a la Reial Audiència. A més a més, s'impedia la reunió dels consells generals de les corporacions sense la presència d'un delegat governatiu designat per l'autoritat territorial competent, és a dir, el corregidor. ${ }^{46}$

A causa de la tensa situació entre les confraries i les autoritats manresanes, Fernando de Guzmán va optar per limitar i exercir un control ferri de les discussions que es feien en les assemblees gremials. Utilitzant les seves prerrogatives, obligava els prohoms a sol-licitar el permís de reunió per escrit, especificant els temes que s'hi discutirien. A més, es negava a enviar delegats a les assemblees gremials, i les presidia sempre ell en persona per ajustar-ne encara més la supervisió. Amb la voluntat de treure's el jou corregimental del damunt, els gremis manresans utilitzaren l'estructura de reclamació establerta pel plet contra els suplements

43. ACBG, AHPM, Notari Jaume Tomàs, lligall 496o, ff. I78v-I79v (I8 de juliol de 1738 ).

44. Ibidem. If. I8or-I8ov (is de juliol de 1738).

45. Ibidem, ff. I80v-I8Ir (20 de juliol de 1738).

46. Jaume Carrera Pujal, Historia política y económica de Cataluña. Siglos XVI al XVIII, Casa editorial Bosch, Barcelona, I947, III, pp. I37-I39; Pere Molas, «El govern dels gremis de Barcelona al segle XVIII ", Revista de Dret Històric Català, I8 (2019), p. II8. 
bagatges per intentar aconseguir el permís de reunir-se sense haver de demanar una autorització escrita al corregidor. ${ }^{47}$

Els nous memorials foren revisats i consultats el dia 2I de novembre del mateix 1738. En l'àmbit dels suplements de bagatges, els magistrats de la Reial Audiència no veieren cap motiu per canviar el seu veredicte anterior, i seguiren mantenint el repartiment dels «retorns». D'altra banda, es mostraren tèbiament sensibles a la denúncia de les males pràctiques comeses pel personal corregimental, instant Fernando de Guzmán i els seus homes que «invigilen y zelen paraque el turno y exacción de el derecho se observe sin cometer el menor fraude».$^{48}$ La Reial Audiència també estudià les demandes per facilitar la convocatòria dels consells generals, així com tots els arguments esgrimits per il.lustrar la neta oposició entre les confraries i el tàndem ajuntament corregidor. Una oposició que, com ho denota la mateixa sentència, ja s'havia demostrat anteriorment amb recursos enviats a l'intendent $\mathrm{i}$ al capità general del Principat. El corregidor també envià esmenes al memorial, recordant les prerrogatives que li reservava la Nova Planta i el fet d'obligar a presentar la demanda de reunió per escrit per evitar la discussió de temes no autoritzats i, sota el seu judici, perjudicials per als gremis. ${ }^{49}$ Així mateix, defensà la seva presència efectiva en les reunions esgrimint l'amenaça d'un possible esclat social "pues fácilmente podían ocasionarse algunas inquietudes según sus genios cavilosos, maÿormente congregándose a vezes más de quatro cientas Personas, en cuyo caso es menester tomar la providencia de estar avisada la tropa». En aquest cas, els oïdors de l'Audiència decidiren interpretar el Decret de Nova Planta de manera literal, accedint a permetre que les llicències per a les reunions poguessin ser orals i sense especificar el tema a discutir, això sí, sempre vigilades pel corregidor mateix o per un ministre seu.

Segurament, el moderat èxit assolit en aquesta darrera ocasió afavorí que els gremis manresans no desistissin en el seu afany d'aconseguir la supressió de l'impost del suplement de bagatges. De la mateixa

47. ACA, RA, Registres, núm. 232, f. I34v (I7 d'octubre deI738).

48. ACA, RA, Registres, núm. I6I, ff. 28r-29r (2I de novembre de 1738).

49. ACA, RA, Registres, núm. I6I, ff. 3or-3Iv (2I de novembre de I738). 
manera, demostrà la viabilitat d'aquesta via de reclamació motivant l'inici d'un llarg plet amb l'objectiu de recuperar les quantitats de diners alienades per males pràctiques en el cobrament del Cadastre entre els anys I72I i I739, protagonitzat per les mateixes corporacions contra les autoritats locals. ${ }^{\circ}$ Emperò, l'esclat de l'afer del Cadastre acabà fent passar l'assumpte dels bagatges a un segon pla.

A finals de l'hivern de $\mathrm{I740}$, Llor i els seus col-laboradors van dirigir els seus esforços a aconseguir testimonis i declaracions del màxim de propietaris d'atzembles de la ciutat renunciant a cobrar els «retorns» de manera particular. La nova estratègia passava per arribar a un nombre suficient de renúncies personals que motivés un canvi de parer dels oïdors de la Reial Audiència. Si això no succeïa però tanmateix s'acceptaven les renúncies, almenys s'alleujaria notablement la quantitat a pagar en cada repartiment.

Entre el 13 i el 20 de març de 1740 van testificar fins a 72 individus manresans a instàncies de Francisco Llor i del notari causídic Pau Casanovas de Barcelona, que s'havia d'encarregar de la gestió de les reclamacions a la capital del Principat. ${ }^{\text {II }}$ El gruix de renúncies eren formalitzades per velers, blanquers i pagesos propietaris d'atzembles. Entre ells, hi havia alguns dels grans terratinents de la ciutat com Josep Oller del Mas o individus de gran importància econòmica dins l'esfera productiva manresana com ara el blanquer, negociant i propietari de molins polvorers Damià Dalmau. ${ }^{52}$ De tots els signants, tan sols hi havia set traginers, del total de 19 que apareixen en el repartiment del Ganancial de I74I..$^{53}$

Tres dies després, el dimecres 23 de març, les renúncies foren copiades i refermades davant del notari barceloní Sever Pujol, deixant clar

50. ACBG, AHPM, Notari Jaume Tomàs, lligall 496I, ff. 219v-22r (30 de juny de I739), ff. 235v-236v (I4 de juliol de I739), ff. 277r-278v, (I4 d'agost de 1739). Aquest plet ja fou esmentat per Josep Maria Torras i Ribé en el seu cèlebre treball sobre els municipis catalans. Torras I Ribé, Els municipis catalans, p. 319.

5I. Vegeu el quadre 2.

52. Llorenç Ferrer Alós, Sociologia de la industrialització. De la seda al cotó a la Catalunya Central (segles XVIII-XIX), Fundació Noguera, Barcelona, 20II, pp. 92-93 i 139. 53. ACBG, AM, Acords, I - 50, s/f (I74I). 
que només renunciaven a les quantitats que els gremis havien d'aportar com a suplement de l'impost, no pas als pagaments fets per la mateixa autoritat militar. ${ }^{54} \mathrm{El}$ nou memorial fou entregat i vist per les autoritats el dia 28 de març. Es reclamà un nou informe sobre l'assumpte a Fèlix Torres de Bages, el tinent de corregidor de la ciutat, el maig següent. ${ }^{5}$ Torres de Bages, doctor en dret civil, ciutadà honrat de Barcelona i regidor de Manresa des de desembre de 1736 , havia substituït en el càrrec Antoni Espona, també ciutadà honrat de Barcelona i d'idèntica formació en drets, el 28 de juny de $1738 .{ }^{56}$

Tant Espona com Torres de Bages foren protagonistes, instigadors i, fins i tot, perpetradors dels excessos comesos per les autoritats corregimentals en la gestió del servei de bagatges. El seu protagonisme anà augmentant al llarg del procés legal, en part gràcies a les contínues absències del corregidor. Aquestes es devien al fet que Fernando de Guzmán, després d'obtenir l'ascens a coronel l'any I739, es trobava en ple procés de sol.licitud per aspirar a la vara corregimental de Jerez de la Frontera, deixant en mans de Torres de Bages la gestió de les matèries més comunes del govern municipal. ${ }^{57}$ Davant de la continuïtat de les resistències al pagament dels «retorns», Torres de Bages es dedicà a enviar requeriments de pagament a cadascun dels gremis de manera continuada. En aquesta situació, el col.legi d'artistes de Manresa sol.licità a la Reial Audiència poder realitzar una talla extraordinària per recaptar les quantitats demandades pel tinent de corregidor. ${ }^{58}$

Ambdues sol.licituds foren resoltes el dia I2 de juny de I740. Els oïdors acceptaren les renúncies dels 72 manresans i ordenaren que tots els instruments notarials que els recollien fossin traslladats a les autoritats locals perquè ho tinguessin en consideració de cara a futurs repar-

54. Arxiu Històric de Protocols de Barcelona (AHPB) 944/26, Notari Sever Pujol, ff. I87r-187v (23 de març de 1740).

55. ACA, RA, Registres, núm. 234, ff. 43r (28 de març de 1740).

56. Cerro NargáneZ, «Una magistratura castellana», pp. I2-I4.

57. GAY Escoda, El corregidor, pp. 647-648.

58. ACA, RA, Registres, núm. 234, ff. 43r-43v (24 de maig de 1740). Aquest gremi agrupava els metges, cirurgians-barbers, apotecaris, especiers, cerers i adroguers. 
timents. En canvi, seguidament especificaren que tots els propietaris d'atzembles que no havien presentat renúncia havien de seguir cobrant els suplements. Per tant, el servei es mantingué. Seguint amb aquesta línia, acceptaren la proposta d'impost extraordinari sol.licitat pel col.legi d'artistes. ${ }^{59}$

Les opcions d'aconseguir una resolució favorable als interessos dels gremis manresans s'havien limitat irremeiablement. L'única opció que els quedava era apel.lar a la màxima autoritat en temes militars, el Supremo Consejo de Guerra. ${ }^{60}$ Per tal de dur a terme les gestions oportunes des de Madrid, Francesc Llor traspassà la seva facultat com a apoderat dels gremis manresans a dos agents de negocis de Madrid, Don Pedro de Rueda Osorio i Don Andrés Prades. ${ }^{61}$

Mentre avançaven els tràmits a la cort, a Manresa la tensió al carrer seguia creixent. El dia 3 d'octubre, mentre els tres prohoms de la confraria de Sant Salvador de pagesos recorrien la ciutat cobrant dels seus agremiats els repartiments fets per sufragar els «retorns» de bagatges, tingueren un important incident amb el tinent de corregidor. En paraules dels testimonis:

[...] quant verem venir nosaltres dits attestants lo Senyor Fèlix Torras de Bages, Thinent de Corregidor de dita Ciutat y a la que arribà $\mathrm{a}[\mathrm{m}] \mathrm{b}$ dits Administradors ohiren los digué dit Senyor que anau rodant per aquí anant enbusterejant consyrosant la gent que si altra vegada vos veig rodar per Manresa a[m]bla llibreta vos posaré $\mathrm{a}[\mathrm{m}] \mathrm{b}$ una cadena al coll, y prengué la llibreta a dit Vila que portava en las mans, dient a dits Administradors que traguessen la llibreta vella que no era aquella la que ells los havia y se l'anporta $[\ldots] .^{62}$

59. ACA, RA, Registres, núm. I63, ff. IIor-IIIv (Io de juny de I740).

6o. Roberto L. Blanco, «Ejército y administración militar en el siglo XviII español», a A. Morales, ed., I7I4. Cataluña en la España del siglo XVIII, Cátedra, Madrid, 20I4, pp. 250-253.

6I. AHPB 944/26, Notari Sever Pujol, ff. 430v-43Ir (22 d'agost de I740).

62. ACBG, AHPM, Notari Jaume Tomàs, lligall 4962, ff. 206r-207r (II d'octubre de 1740 ). 
No era la primera vegada que Torres de Bages actuava d'aquesta manera. Un any abans ja havia atacat físicament un dels cònsols del collegi d'artistes, Eudald Tor. Quan Tor respongué amb evasives algunes de les seves preguntes:

[...] dit Senyor Thinent de Corregidor $\mathrm{a}[\mathrm{m}] \mathrm{b}$ grandíssima fúria agarrà a dit Eudald Tor per lo coll per la part de la garganta cridant a[m]b alta veu dient lo escanyaré y que a $[\mathrm{m}] \mathrm{b}$ una garrotada li trauré lo servell del cap, [...] dit Senyor Thinent de Corregidor estava ja a[m]b lo bastó alt pera pagarli y dexantlo despues del modo lo havia agarrat viu se passejà un gran rato ohint li deÿa paraules molt injurioses y gravatorias entre altres ohí li digué que era un Alborotador del Poble fent grans maneos y amenasses de mans y bastó y a[m]b gran picament de peus. ${ }^{63}$

Les males pràctiques $\mathrm{i}$ les amenaces no sempre es presentaven d'una manera tan crua i directa. La vehemència de Francisco Llor a l'hora de plantejar les reclamacions de les confraries manresanes no passà desapercebuda per les autoritats territorials. D'aquesta manera, fins i tot l'intendent Antoine de Sartine va decidir actuar per mirar d'encarrilar la situació. El seu objectiu, comunicat al corregidor Fernando de Guzmán per carta, era pressionar els gremis manresans per fer-los retirar la delegació de poders a Llor «elegint en son lloch altre subjecte gens cabilós ${ }^{64} \mathrm{y}$ de bona intensio $\mathrm{a}[\mathrm{m}] \mathrm{b}$ qui poguessen tractar sempre que convingués». ${ }^{65}$ Quan aquesta proposta fou traslladada al consell general de la confraria de Sant Antoni Abat de sabaters, fou vehementment rebutjada pels agremiats.

La incertesa s'allargà uns mesos més, fins a la resolució del Supremo Consejo de Guerra que, per bé que fou presa el 3 de setembre de 1740, no va ser comunicada públicament a Catalunya fins el dia i8 d'abril de

63. ACBG, AHPM, Notari Jaume Tomàs, lligall 496r, ff. 249r-25or (23 de juliol de 1739).

64. Paraula ratllada en el manuscrit original.

65. ACBG, AHPM, Notari Francesc Ratllat i Fargas, lligall 4980, ff. 8v-9r (I de gener de I74I). 
I74I ${ }^{66}$ Els resultats no foren els desitjats pels demandants, ans al contrari. El dictamen tancà completament la porta a qualsevol opció d'acabar amb els suplements de bagatges. En els prolegòmens de la resolució, els consellers es feien ressò de tot el procés des de juny de I738, posant en valor les declaracions i els dictàmens de la Reial Audiència de Catalunya, com també l'existència d'una acceptació tàcita del suplement de «retorn» de bagatges entre els anys I7I9 i I737 per part de les confraries manresanes. Més endavant, passaren a discutir les diverses apel.lacions formalitzades per Francisco Llor i la seva feblesa argumental, fet que impedia canviar les resolucions preses anteriorment. Els consellers es basaven en el fet que els canvis instaurats a partir de la publicació de la reial cèdula de Io de març de 1740 titulada «Sobre los bagages con que los Pueblos deben assistir a la Tropa y precios a que ésta los ha de satisfacer» ja oferien un marc legal vàlid que recollia part de les demandes manresanes.

Tant la continuïtat dels excessos i les males pràctiques com el més que previsible augment de la pressió militar a causa de la guerra amb la Gran Bretanya i d'una més que probable ramificació continental del conflicte motivaren una nova reformulació de les ordenances al voltant del servei de bagatges. En aquesta ocasió es modificà l'element clau del preu a pagar per cada servei, canviant el preu taxat per tipus de bagatge a una quantitat estipulada per llegua transitada. ${ }^{67}$ Malauradament, com en el mateix dictamen del Consell de Guerra s'esmenta, «todavía no se ha podido poner en práctica por no haber cumplido las Reales Thesorerías, al tiempo de moverse los cuerpos el anticiparles con el pré[st], lo que se computasse preciso para la satisfacción de los bagajes como con el mismo decreto mando Su Majestad».

De la mateixa manera, la resolució se centrava en els repartiments executats per les autoritats gremials com l'autèntica arrel del problema. Deixava clara la iniciativa original de les confraries a oferir el suplement i derivà la responsabilitat dels desajustos i les diferències en les

66. ACA, RA, Registres, núm. I64, ff. 96v-99r (I8 d'abril de I74I).

67. Un ral i mig per llegua de cavalleria major i un ral de billó per llegua de cavalleria menor. PORTugués, Colección General, III, p. 409. 
quantitats pagades per cada agremiat als administradors. Per acabar-ho de reblar, assenyalà el corregidor i els seus oficials com a instància prioritària de reclamació a qui s'havien de dirigir els agremiats descontents amb els repartiments, obviant qualsevol esment dels excessos comesos pel tinent de corregidor i els seus agutzils. A més a més, els consellers apuntaren que les quantitats a cobrar mai havien arribat a les xifres que reclamaven els gremis manresans, insistint que cada agremiat contribuïa una sola vegada a l'any $\mathrm{i}$, com a màxim, pagant fins a cinc sous.

Finalment, la resolució rebaixà la importància de les 72 renúncies presentades, recalcant-ne el caràcter personal i que no constituïen una majoria dins del conjunt de propietaris d'atzembles de la ciutat. Així doncs, aquestes renúncies no podien afectar cap altre propietari més enllà dels mateixos signants. Més encara, els consellers es feien ressò de l'existència d'un plet en curs a la sala criminal de la Reial Audiència de Catalunya contra Francisco Llor per haver fet falses promeses a deu dels renunciants. Segons versen les darreres línies de la sentència, Llor els convencé d'anar a testificar davant del notari «que con ello no irían más á bagaje y haviendo ido no hizieron otra cosa que presentarse; Y tomarles el escribano el nombre, sin hablarles palabra por lo que niegan haver dado tales poderes al citado Llor, y incisten en querer obtener los suplementos».

\section{Conclusions}

La cruesa del veredicte del Supremo Consejo de Guerra marcà la fi del procés de reclamació dels gremis manresans per lliurar-se dels suplements de bagatges. A partir d'aquell moment, els prohoms de les confraries decidiren dedicar tots els seus esforços a aconseguir millors resultats en l'esmentat plet del Cadastre, en què la finestra d'oportunitat i les possibilitats d'èxit i d'apel.lació eren molt més vives, i els eventuals guanys molt més substancials. ${ }^{68}$ Tot i el topall institucional i la

68. Cal tenir present que la quantitat a què arribà el desfalc dels regidors locals fou de I58.190 rals d'ardit en un total de I8 anys. Torras i Ribé, Misèria, poder, pp. 77 i 107. 
infructuosa apelllació final, les accions de Llor aconseguiren rebaixar part del pes econòmic dels «retorns» a través de les renúncies personals. Alhora, mitjançant l'establiment de relacions fluides amb notaris reials i causídics de Barcelona i el nomenament de procuradors a la cort de Madrid, els gremis manresans acabaren conformant una estructura reivindicativa que sobrevisqué al fracàs de la demanda inicial, i permetria vehicular noves protestes i demandes.

Amb tot, la lluita legal descrita fins ara ens permet illustrar una de les dinàmiques més pròpies de l'establiment del règim borbònic a $\mathrm{Ca}$ talunya: la legalització, la codificació i l'adequació en posterioritat - i de manera generalment reactiva- d'imposicions i normatives originalment provisionals i nascudes de l'excepcionalitat militar. Unes disposicions que, evidentment, generaren greus tensions i daltabaixos a causa del seu manteniment continuat en el temps. Els «retorns» de bagatges plantejats el I719 en l'àmbit estrictament local pels gremis manresans com una gràcia cap al Reial Servei seguiren essent pagats puntualment gràcies al costum $i$ consuetud, no pas en base a cap directiva legal. Fou precisament la demanda encapçalada per les confraries la que acabà derivant en una legislació vertical que blindava els suplements ja no com una gràcia o servei, sinó com un veritable impost.

El creuament de la documentació institucional generada per l'ajuntament, la cort del corregidor i la Reial Audiència amb els registres notarials ha permès conèixer millor alguns dels arguments de resistència emprats en els diversos memorials i súpliques que generà el procés, anant des del més estricte legalisme fins a l'adducció d'arguments de caire purament econòmic. Els excessos propis de la fiscalitat local foren marcadament recurrents en altres protestes i litigis contemporanis al cas manresà. Bona part de les demandes i crítiques que els instigaren sorgiren precisament com una reacció vers aquelles càrregues pròpies de l'administració militar o fiscal — les quintes, els allotjaments, les lleudes extraordinàries o les desigualtats en el pagament del Cadastreque resultaven particularment costoses per les economies de les capes més humils de la població.

Un exemple clar el trobaríem a la Tarragona de 1754, quan l'ajuntament de la ciutat intentà afermar noves imposicions sobre l'entrada de 
mercaderies com el peix fresc, el pa o els vins forans emparant-se en un privilegi concedit per Alfons el Magnànim el I437. ${ }^{69}$ Els arguments presents als memorials dels regidors feien referència als beneficis que aquestes imposicions tenien pels interessos del Reial Servei i que es destinaven des de I7I9 al pagament de les reparacions de les fortificacions i els camins de la ciutat, així com a pagar els deutes contrets per la mateixa causa. ${ }^{70}$ Aquesta iniciativa despertà una greu commoció popular i generà un front comú dels gremis locals similar a l'observada a Manresa. ${ }^{71}$ La naturalesa eminentment nobiliària, privilegiada i poc permeable dels ajuntaments de ciutats com Tarragona o Manresa, a diferència dels consistoris de viles més petites, motivava que la pràctica totalitat dels regidors i els seus oficials es trobessin exempts tant de certes imposicions locals com de les reials i que tendissin a mostrar-se poc sensibles a l'esmentada problemàtica. ${ }^{72}$ D'aquesta manera, no resulta estrany que la reacció i posterior mobilització envers aquest tipus d'imposicions fos instigada per agents externs a l'administració municipal, com ho eren els gremis catalans des de les reformes de I7I6 i I718. ${ }^{73}$ Aquesta circumstància, com ja s'ha fet palès, és compartida per bona part dels esclats i protestes tant corporatives com populars que es

69. ACA, RA, Registres, núm. 475, ff. 266r (20 de juliol der754).

70. Ibidem, ff. 268r-268v (20 de juliol de 1754).

7I. TORRAS I RibÉ, Els municipis catalans, p. 320.

72. Joaquim SARret I Arbós, Història l'estat polític-social de Manresa, Impremta Sant Josep, Manresa, I925, pp. 54-58. Marc Torras I SERra, "Les institucions del poder a la Manresa dels segles XviI i XviII», a M. Torras i Serra, coord. Manresa de la Guerra dels Segadors a la Guerra Gran, Centre d'Estudis del Bages, Manresa, 20I4, pp. I03-IO5.

73. No succeí el mateix en altres poblacions més petites que contemporàniament sollicitaren un alleujament del servei de bagatges. En els casos de Riudoms i Ulldecona (174I), foren els regidors locals els que encapçalaren les reivindicacions. ACA, RA, Registres, núm. 234, ff. 45r (I d'abril de I74I) i ff. 87r (I8 de juliol de I74I). Per altra banda, les denúncies i reclamacions sobre el servei de bagatges no sempre es feien a través d'òrgans colllegiats o institucionals. Per exemple, l'any I738, un cirurgià del corregiment de Mataró, Domingo Palaudarias, havia presentat de manera personal l'exempció del servei per haver de disposar del seu ruc per visitar els malalts. ACA, RA, Registres, núm. 232, ff. I5Iv (9 de novembre de 1738). 
donaren a les dècades de $\mathrm{I} 740$ i 1750 arreu del territori català i que han estat estudiades per Josep Maria Torras i Ribé, Enric Tello, Lluís Roura i Pere Molas. ${ }^{74}$ En la majoria d'ocasions, aquests prohoms i membres de les confraries d'oficis locals, com el manresà Francesc Llor, intentaren aconseguir la mitigació o la desaparició de les esmentades càrregues servint-se de tots els mecanismes de reclamació possibles dins l'estructura burocràtica de la Nova Planta.

Amb tot, l'allargament dels processos, l'oberta oposició d'ajuntaments i corregidors a qualsevol mena de cessió i la consegüent tensió social que tot això acabava generant, afavoriren que aquests plets i reclamacions de caràcter eminentment econòmic en la seva concepció inicial es convertissin alhora en una plataforma de crítica i censura de les males pràctiques generalitzades executades per les esmentades autoritats locals. A més del cas que ens ocupa, també són un bon exemple d'aquesta dinàmica les protestes i els plets que s'esdevingueren a Miravet i a Cervera el 1745 i a Sabadell el 1759. ${ }^{75}$

Tot i així, les reivindicacions manresanes no semblen haver pres el matís de radicalitat pràcticament insurreccional que sí que caracteritzà alguns d'aquests altres moviments. Alguns d'ells, com el que es donà a Banyoles l'any I750, se serviren dels tradicionals mecanismes de mobilització social com el toc a sometent de les campanes de l'església i els crits de «botiflers» que es llançaren contra les autoritats locals com ho recull la documentació de la Reial Audiència. ${ }^{76} \mathrm{~A}$ hores d'ara, no s'ha localitzat cap conat de revolta similar per l'exemple manresà ni en la documentació administrativa ni en la notarial consultada als arxius de

74. Són ben coneguts gràcies als esmentats autors els casos de Cervera contra les quintes de 1740-1743/54 a Enric Tello, Visca el Rei, pp. 192-272, i el cas dels gremis de Mataró contra els impostos extraordinaris a Pere Molas, Societat i poder, pp. Io9III i II7-I3I. Per a més referències sobre les resistències a les quintes a mitjans del segle xviII, vegeu Roura, Subjecció i revolta, pp. 95-I07.

75. Torras i Ribé, Els municipis catalans, p. 320.

76. ACA, RA, Registres, núm. 470, ff. 95r-95v (5 de setembre de 1750). Document citat a Torras i Ribé, Misèria, poder, pp. I07-IO8. Els exemples de Cervera el I745, Tarragona el I760 i Begur el I76I són també esmentats a ToRRAS I RibÉ, Els municipis catalans, pp. 32I-322. 
Barcelona i Manresa. Tanmateix, l'amenaça d'un possible desbordament de la tensió sempre hi va estar present, tal com es desprèn de les raons adduïdes pel corregidor Fernando de Guzmán per continuar controlant atentament les reunions de les confraries manresanes. ${ }^{77}$

Sens dubte, el plet pels «retorns» dels bagatges iniciat per Francesc Llor i el gremi de Nostra Senyora del Remei de velers, galoners i cordoners de Manresa constitueix un exemple primerenc però no per això menys il.lustratiu d'aquest corol.lari reivindicatiu que a partir de la dècada de 1740 es deixà sentir arreu del país posant en tensió les costures de l'encara recent Nova Planta institucional. Tot i la seva cronologia breu i els seus resultats modestos, l'anàlisi de les estratègies reivindicatives de les confraries manresanes permet conèixer una mica més les llums i ombres del procés d'assentament del nou règim borbònic a Catalunya, i il.lustra — des de l'òptica local— l'existència d'una tensió cada vegada més patent entre l'administració territorial i una part de la societat catalana que, lluny d'aquietar-se, procurà utilitzar tots els mecanismes institucionals a la seva disposició per lluitar contra els abusos governatius i deslliurar-se d'algunes de les conseqüències econòmicament més oneroses causades per la important presència militar existent al Principat, tant en guarnició com en trànsit, des de la fi del conflicte successori.

QUADRE I. Serveis de bagatges organitzats pel corregidor de Manresa (1733-1738) ${ }^{78}$

\begin{tabular}{|l|l|l|l|}
\hline $\begin{array}{l}\text { Data de } \\
\text { la firma }\end{array}$ & \multicolumn{1}{|c|}{ Unitat } & \multicolumn{1}{|c|}{ Origen } & \multicolumn{1}{c|}{ Destí } \\
\hline I6-I0-I733 & Primer batalló del regiment d'infanteria de Sevilla & Manresa & Martorell \\
\hline I8-04-I734 & Segon batalló del regiment d'infanteria de Sevilla & Manresa & No s'esmenta \\
\hline I9-04-I734 & Un batalló del regiment d'infanteria de Limerick & Castellar & No s'esmenta \\
\hline
\end{tabular}

(Continua a la pàgina següent)

77. Vegeu la nota 48.

78. Font: Arxiu de la Seu de Manresa (ASM), Corregiment,V-32, (1730-1734) i $V-36$ (I735-1740). En aquest còmput no hi entren els trànsits de tropes organitzats des de Berga pel tinent de corregidor situat a la vila. 


\begin{tabular}{|c|c|c|c|}
\hline $\begin{array}{l}\text { Data de } \\
\text { la firma }\end{array}$ & Unitat & Origen & Destí \\
\hline 04-05-1734 & Segon batalló del regiment d'infanteria de Sevilla & Manresa & No s'esmenta \\
\hline 19-08-1734 & $\begin{array}{l}\text { Primer i segon batallons del regiment d'infanteria } \\
\text { d'Astúries }\end{array}$ & Manresa & Cardona i Berga \\
\hline I6-OI-I735 & Segon batalló del regiment d'infanteria de Mallorca & Manresa & Moià \\
\hline I7-OI-I735 & Primer batalló del regiment d'infanteria d'Astúries & Manresa & Barcelona \\
\hline II-02-I735 & Primer batalló del regiment d'infanteria de Mallorca & Manresa & $\begin{array}{l}\text { Seu d'Urgell i } \\
\text { Berga }\end{array}$ \\
\hline $17-02-1735$ & Segon batalló del regiment d'infanteria de Mallorca & Manresa & Barcelona \\
\hline I3-03-I735 & Sis companyies del regiment de cavalleria de Brabant & Manresa & No s'esmenta \\
\hline $20-03-1735$ & Sis companyies del regiment de cavalleria de Brabant & Manresa & No s'esmenta \\
\hline 06-10-1735 & Primer batalló del regiment d'infanteria de Catalunya & Manresa & Cardona \\
\hline 08-10-1735 & Segon batalló del regiment d'infanteria de Catalunya & Manresa & Cardona \\
\hline II-IO-I735 & Primer batalló del regiment d'infanteria de Mallorca & Manresa & Barcelona \\
\hline $14-04-1736$ & Primer batalló del regiment d'infanteria de Vitória & Manresa & No s'esmenta \\
\hline 16-04-1736 & Primer batalló del regiment d'infanteria d'Àfrica & Manresa & Cardona \\
\hline 05-02-1737 & Primer batalló del regiment d'infanteria de Navarra & Manresa & No s'esmenta \\
\hline 07-02-1737 & Segon batalló del regiment d'infanteria de Navarra & Manresa & No s'esmenta \\
\hline II-02-I737 & $\begin{array}{l}\text { Primer batalló del regiment d'infanteria de } \\
\text { Llombardia }\end{array}$ & Manresa & No s'esmenta \\
\hline I4-02-1737 & Segon batalló del regiment d'infanteria de Llombardia & Manresa & No s'esmenta \\
\hline 3I-03-1737 & Regiment de dragons de Batàvia & $\begin{array}{l}\text { Monistrol de } \\
\text { M. }\end{array}$ & Manresa \\
\hline 03-09-1737 & $\begin{array}{l}\text { Sis companyies del regiment de cavalleria } \\
\text { d'Extremadura }\end{array}$ & $\begin{array}{l}\text { Sant Fruitós } \\
\text { de Bages } \\
\end{array}$ & Moià \\
\hline $\begin{array}{ll}06-09- \\
1737\end{array}$ & $\begin{array}{l}\text { Sis companyies del regiment de cavalleria } \\
\text { d'Extremadura }\end{array}$ & Moià & No s'esmenta \\
\hline 25 -IO-I737 & Regiment de cavalleria de Borbó & Manresa & No s'esmenta \\
\hline I5-II-I737 & $\begin{array}{l}\text { Sisè batalló del regiment d'infanteria de Guàrdies } \\
\text { Espanyoles }\end{array}$ & Manresa & No s'esmenta \\
\hline I6-II-I737 & $\begin{array}{l}\text { Cinquè batalló del regiment d'infanteria de Guàrdies } \\
\text { Espanyoles }\end{array}$ & Manresa & No s'esmenta \\
\hline II-05-I738 & Un batalló del regiment d'infanteria de l'Àfrica & $\begin{array}{l}\text { Prats de } \\
\text { Lluçanès }\end{array}$ & Girona \\
\hline
\end{tabular}

(Continua a la pàgina següent) 


\begin{tabular}{|l|l|l|l|}
\hline $\begin{array}{c}\text { Data de } \\
\text { la firma }\end{array}$ & \multicolumn{1}{|c|}{ Unitat } & \multicolumn{1}{|c|}{ Origen } & \multicolumn{1}{|c|}{ Destí } \\
\hline II-05-1738 & Un batalló del regiment d'infanteria de l'Àfrica & Moià & Girona \\
\hline 2I-05-1738 & Un esquadró del regiment de cavalleria de Borbó & Sallent & No s'esmenta \\
\hline 22-05-I738 & Un esquadró del regiment de cavalleria de Borbó & Castellterçol & No s'esmenta \\
\hline 28-05-I738 & $\begin{array}{l}\text { Un destacament del regiment de cavalleria } \\
\text { d'Extremadura }\end{array}$ & Manresa & No s'esmenta \\
\hline 3I-05-1738 & Set companyies del regiment d'infanteria de l'Àfrica & Manresa & No s’esmenta \\
\hline 3I-05-1738 & Un batalló del regiment d'infanteria de l'Àfrica & Sallent & No s'esmenta \\
\hline I3-06-I738 & Regiment de cavalleria de Malta & Castellterçol & Moià \\
\hline I4-06-I738 & Regiment de cavalleria de Malta & Moià & Calders \\
\hline I5-06-I738 & Regiment de cavalleria de Malta & Calders & Manresa \\
\hline
\end{tabular}

\section{QUADRE 2. Llista dels 72 propietaris d'atzembles que renuncien als «retorns» de Bagatges $(\mathbf{I} 740)^{79}$}

\begin{tabular}{|c|l|l|l|c|}
\hline $\begin{array}{c}\text { Dia de la } \\
\text { firma }\end{array}$ & Nom & \multicolumn{1}{|c|}{ Cognom } & $\begin{array}{c}\text { Sap } \\
\text { llegir? }\end{array}$ \\
\hline I4-III-I740 & Ignasi & Altamiras & Pagès & Sí \\
\hline I3-III-I740 & Josep & Barjau & Calderer & Sí \\
\hline I4-III-I740 & Felip Neri & Barjau & Calderer & No \\
\hline I7-III-I740 & Fruitós & Bohigues & Veler & Sí \\
\hline I9-III-I740 & Francesc & Cabanes & Traginer & No \\
\hline I4-III-I740 & Gaspar & Cardoliver i Tardà & Sabater & Sí \\
\hline I3-III-I740 & Maurici & Casamitjana & Paraire & Sí \\
\hline I3-III-I74I & Fèlix & Cases & Veler & Sí \\
\hline I7-III-I740 & Miquel & Coll & Ferrer & Sí \\
\hline I4-III-I740 & Pere & Colldeforns (major de dies) & Soguer & Sí \\
\hline I4-III-I740 & Onofre & Coma & Blanquer & Sí \\
\hline I4-III-I740 & Domènec & Coma & Blanquer & Sí \\
\hline
\end{tabular}

(Continua a la pàgina següent)

79. Font: ACBG, AHPM, Notari Jaume Tomàs, lligall 4962, ff. 67r-79r (I3 de març de 1740 a 20 de març de 1740 ). 


\begin{tabular}{|c|c|c|c|c|}
\hline $\begin{array}{c}\text { Dia de la } \\
\text { firma }\end{array}$ & Nom & Cognom & Ofici & $\begin{array}{c}\text { Sap } \\
\text { llegir? }\end{array}$ \\
\hline I7-III-I740 & Maurici & Coma & Clavetaire & Sí \\
\hline I7-III-I740 & Ignasi & Coma & Blanquer & Sí \\
\hline I4-III-I740 & Gerònim & Comelles & Soguer & Sí \\
\hline I4-III-I740 & Tomàs & Cots & Pagès & No \\
\hline I7-III-I740 & Jaume & Culla & Ferrer & No \\
\hline I3-III-I740 & Damià & Dalmau & Blanquer & Sí \\
\hline I4-III-I740 & Joan & Dalmau & Blanquer & Sí \\
\hline I4-III-I740 & Miquel & Dalmau & Blanquer & Sí \\
\hline I4-III-I740 & Tomàs & Dalmau & Blanquer & Sí \\
\hline I3-III-I740 & Joan & Enric & Veler & Sí \\
\hline I4-III-I740 & Ramon & Enric & Traginer & Sí \\
\hline I4-III-I740 & Francesc & Febrés & Blanquer & No \\
\hline I4-III-I740 & Fruitós & Febrés & Veler & $S_{1}^{\prime}$ \\
\hline I4-III-I740 & Joan & Ferreres & Pagès del terme de Manresa & $S_{1}^{\prime}$ \\
\hline I9-III-I740 & Maurici & Ferreres & Pagès & No \\
\hline I4-III-I740 & Magí & Firmat & Argenter & Sí \\
\hline I3-III-I740 & Simó & Font & Veler & No \\
\hline I4-III-I740 & Fèlix & Font & Pagès & No \\
\hline I9-III-I740 & Josep & Font & Pagès & No \\
\hline I9-III-I740 & Ramon & Font & Pagès & Sí \\
\hline I7-III-I740 & Albert & Galí & Pagès & No \\
\hline I9-III-I740 & Esteve & Jové & Traginer & No \\
\hline I3-III-I740 & Jaume & Jovells & Pagès & No \\
\hline I3-III-I740 & Josep & Llussà & Paraire & Sí \\
\hline 20-III-I740 & Miquel & March (major de dies) & Veler & No \\
\hline I9-III-I740 & Magí & Martí & Veler & Sí \\
\hline I9-III-I740 & Alexandre & Miralda & Traginer & No \\
\hline I9-III-I740 & Antoni & Monconill & Pagès & No \\
\hline I7-III-I740 & Jaume & Morera (major de dies) & Pagès & Sí \\
\hline I4-III-I740 & Fruitós & Morros & Confiter & No \\
\hline I7-III-I740 & Jacint & Morros & Clavetaire & No \\
\hline
\end{tabular}

(Continua a la pàgina següent) 


\begin{tabular}{|c|c|c|c|c|}
\hline $\begin{array}{l}\text { Dia de la } \\
\text { firma }\end{array}$ & Nom & Cognom & Ofici & $\begin{array}{c}\text { Sap } \\
\text { llegir? }\end{array}$ \\
\hline I7-III-I740 & Ignasi & Oliveres & Pagès & No \\
\hline I7-III-I740 & Valentí & Oliveres & $\begin{array}{l}\text { Pagès del mas de Suanya de } \\
\text { Manresa }\end{array}$ & No \\
\hline I4-III-I740 & Josep & Oller del Mas & Pagès del terme de Manresa & Sí \\
\hline I7-III-I740 & Joan & Passola & Pagès & No \\
\hline I4-III-I740 & Andreu & Perera & Blanquer & Sí \\
\hline I4-III-I740 & Maurici & Perera & Blanquer & No \\
\hline I4-III-I740 & Maurici & Perera & Blanquer & Sí \\
\hline I4-III-I740 & Jaume & Perramon & Pagès & No \\
\hline I7-III-I740 & Josep & Perramon & Pagès & No \\
\hline I9-III-I740 & Bonifaci & $\mathrm{Pla}$ (menor de dies) & Veler & Sí \\
\hline I4-III-I740 & Macià & Pons & Blanquer & Sí \\
\hline I4-III-I740 & Joan & Puig & Veler & Sí \\
\hline I7-III-I740 & Agustí & Renalies & Pagès & No \\
\hline I7-III-I740 & Josep & Ribas & Veler & Sí \\
\hline I7-III-I740 & Pere Joan & Roberge & Forner & Sí \\
\hline I7-III-I740 & Joan & Santllehí & Ferrer & No \\
\hline 20-III-I740 & Miquel & Serra & Traginer & No \\
\hline I3-III-I740 & Pau & Socas & Sastre & No \\
\hline I4-III-I740 & Francesc & Soler & Blanquer & Sí \\
\hline I4-III-I740 & Josep & Soler & Pagès & No \\
\hline I4-III-I740 & Fèlix & Tarrida & Pagès & No \\
\hline I7-III-I740 & Valentí & Torras & Ferrer & No \\
\hline I9-III-I740 & Jaume & Torras & Pagès & No \\
\hline 20-III-I740 & Jaume & Valls & Traginer & Sí \\
\hline I7-III-I740 & Ramon & Vedrenes & Pagès & No \\
\hline I9-III-I740 & Maurici & Vila & Traginer & No \\
\hline I4-III-I740 & Francesc & Viladerans & Veler & Sí \\
\hline I4-III-I740 & Carles & Vilatorrada & Veler & Sí \\
\hline I9-III-I740 & Valentí & Vives & Pagès & No \\
\hline
\end{tabular}

